\title{
Ocorrência sorológica de Babesia bovis, Babesia bigemina e Anaplasma marginale em bovinos e bubalinos no estado do Pará, Brasil
}

\section{Serological occurrence of Babesia bovis, Babesia bigemina and Anaplasma marginale in cattle and water buffaloes of Pará, Brazil}

\author{
Jenevaldo Barbosa da Silva ${ }^{1 *}$; Matheus Dias Cordeiro ${ }^{2}$; Gustavo Nunes de Santana \\ Castro $^{2}$; Priscilla Nunes dos Santos ${ }^{2}$; Adivaldo Henrique da Fonseca ${ }^{3}$; \\ Alessandra Belo Reis ${ }^{4}$; Natália Silva e Silva ${ }^{4}$; José Diomedes Barbosa ${ }^{5}$
}

\section{Resumo}

\begin{abstract}
Dentre as principais enfermidades que acometem bovinos e bubalinos, destacam-se as doenças transmitidas por carrapatos. As babesioses bovinas, causadas por Babesia bigemina e Babesia bovis, e a anaplasmose, causada pela rickettsia Anaplasma marginale, são doenças de grande importância econômica para a bovinocultura. O objetivo deste trabalho foi comparar a ocorrência sorológica para os agentes da Tristeza Parasitária em bovinos e bubalinos na mesorregião sudeste do estado do Pará, região norte do Brasil. Foram efetuadas coletas de sangue de 679 bovinos de corte (Nelore) e 430 bubalinos (Mediterrâneo e Murrah) em oito cidades da mesorregião do sudeste do estado do Pará, Brasil. A pesquisa de anticorpos da classe IgG contra A. marginale, B. bigemina e $B$. bovis foi realizada por Ensaio de Imunoadsorção Enzimático Indireto (iELISA). Bovinos, quando comparados a bubalinos, apresentaram maior ocorrência de anticorpos contra B. bovis (97,34\% e 33.95\%), B. bigemina $(97,34 \%$ e $27.21 \%$ ) e $A$. marginale (74,52\% e 47.90\%), respectivamente. O número de bovinos soropositivos para $A$. marginale, B. bovis e B. bigemina foi 1,5 (74,52/47,90\%), 3,58 (97,34/27,21\%) e 2,87 (97,34/33,95\%) vezes maior do que os bubalinos, respectivamente. Os resultados permitem concluir que, habitando a mesma mesorregião e sendo submetidos a mesma pressão de vetores e agentes, os bubalinos apresentaram ocorrência de anticorpos contra os agentes da TPB inferior aos bovinos. Esses resultados sugerem que os búfalos podem ser mais resistentes aos vetores sendo submetidos a uma menor taxa de infecção que os bovinos.
\end{abstract}

Palavras-chave: Anaplasmose, Babesiose, bovinos nelore, búfalo d'agua

\footnotetext{
Abstract

Among the major diseases that affect cattle and water buffaloes, the tick-borne diseases are detaches. Bovine babesiosis caused by Babesia bigemina and Babesia bovis, and anaplasmosis, caused by Anaplasma marginale rickettsia, are of great economic importance to cattle diseases. The aim of this study was to compare the serologic occurrence for the agents of tick fever in cattle and water buffaloes

1 Discente da Faculdade de Ciências Agrárias e Veterinária, Universidade Estadual Paulista, FCAV/UNESP, Jaboticabal, SP. E-mail: jenevaldo@hotmail.com

2 Discentes da Universidade Federal Rural do Rio de Janeiro, UFRRJ, Seropédica, RJ. E-mail: mathcordeiro@hotmail.com; gnscastro@hotmail.com; priscillanunes@rocketmail.com

3 Prof., UFRRJ, Seropédica, RJ. E-mail: adivaldo@ufrrj.br

4 Discentes da Universidade Federal do Pará, UFPA, Castanhal, PA. E-mail: alessandra_belo22@hotmail.com; nataliasilva@ufpa.br

5 Prof., UFPA, Castanhal, PA. E-mail: diomedes@ufpa.br

Autor para correspondência
} 
in the middle region southeast of the state of Pará, northern Brazil. Blood samples were collected from 679 beef cattle (Nelore) and 430 water buffaloes (Mediterranean and Murrah) in eight cities of middle region southeast of Pará, Brazil. The research of antibodies IgG against A. marginale, B. bigemina and $B$. bovis was performed through of the indirect enzyme-linked immunosorbent assay (iELISA). Cattle compared to buffaloes showed higher occurrence of antibodies against B. bovis $(97,34 \%$ and $33.95 \%)$, B. bigemina (97,34\% and $27.21 \%$ ) and A. marginale (74,52\% and $47.90 \%)$, respectively. The probability of cattle are serologically positive to A. marginale, B. bovis and B. bigemina was $1,5(74,52 / 47,90 \%), 3,58(97,34 / 27,21 \%)$ and $2,87(97,34 / 33,95 \%)$ times higher than that buffaloes, respectively. These results suggest that buffaloes may be more resistant to vectors being subjected to a lower rate of infection than cattle.

Key words: Anaplasmosis, Babesiosis, nelore bovine, water buffaloes

\section{Introdução}

A bovinocultura brasileira tornou-se um destaque no cenário mundial, visto que o Brasil detém o posto de maior rebanho comercial do mundo, respondendo por aproximadamente 200 milhões de cabeças. O rebanho bubalino brasileiro, por sua vez, está estimado em torno de 1,15 milhão de animais, sendo, portanto, o maior rebanho de búfalos da América Latina. A bubalinocultura brasileira encontra-se em franca expansão, visto que os búfalos se adaptam facilmente a diferentes ambientes, sendo assim, uma alternativa rentável para os produtores em locais onde os bovinos não são produtivos.

A região Norte do Brasil responde por 44,35 milhões de bovinos e 770 mil bubalinos, e o estado do Pará detém sozinho 22\% (9,76 milhões) e 39\% (300,3 mil) do rebanho nacional de bovinos e bubalinos, respectivamente.

Dentre as principais enfermidades que acometem bovinos e bubalinos, destacam-se as doenças transmitidas por carrapatos. As babesioses bovinas, causadas por Babesia bigemina e Babesia bovis, e a anaplasmose, causada pela riquétisa Anaplasma marginale, são doenças de grande importância econômica para a bovinocultura (BOCK et al., 2004). A infecção concomitante por estes três agentes etiológicos é de ocorrência comum em bovinos e caracteriza a enfermidade conhecida como Tristeza Parasitária Bovina (TPB), responsável por perdas significativas com a mortalidade de animais, diminuição da produção e com os gastos na aplicação de medidas para seu controle. Os bubalinos são considerados resistentes ao desenvolvimento de doenças causadas pelos agentes da TPB, podendo atuar como reservatório destes agentes (TERKAWI et al., 2011; SILVA et al., 2013a,b). No entanto, bezerros búfalos podem desenvolver sintomas quando se encontram em condições adversas. Sendo assim, o objetivo deste trabalho foi comparar a ocorrência sorológica para os agentes da TPB em bovinos e bubalinos na mesorregião sudeste do estado do Pará, região norte do Brasil.

\section{Material e Métodos}

O estudo foi realizado entre fevereiro e março do ano de 2012, em diferentes propriedades de oito cidades da Mesorregião do Sudeste do estado do Pará, região norte do Brasil: Marabá, Itupiranga, Xinguara, Rio Maria, Curionópolis, Santa Maria das Barreiras, Bannach e Água Azul do Norte. Foram efetuadas coletas de sangue de 679 bovinos de corte, da raça nelore, e 430 bubalinos, das raças Mediterrâneo e Murrah, ambas as espécies eram criadas a pasto no sistema de criação extensiva. Foram avaliadas cinco propriedades rurais em cada um dos oito Municípios, sendo selecionados aleatoriamente entre 8 e 25 animais por propriedade (Tabela 1).

A pesquisa de anticorpos da classe IgG contra A. marginale, B. bigemina e $B$. bovis foi realizada segundo Machado et al. (1997), Silva et al. (2013a) e Silva et al. (2014). Como controles positivos foram utilizados soros de bovinos e bubalinos com altos títulos de anticorpos para os agentes testados. 
Como controles negativos foram utilizados soros de bovinos e bubalinos recém-nascidos que não ingeriram o colostro e que foram considerados negativos quando previamente testados. O "cut off" foi calculado baseado no soro de 30 animais controles negativos, através do receiver operating characteristic (ROC) analisado com o software estatístico MedCalc (version 11.4; http://www. medcalc.behttp://www.medcalc.be) (TERKAWI et al., 2011).

Tabela 1. Distribuição das populações de bovinos e búfalos estudadas na Mesorregião Sudeste do Estado do Pará, Brasil.

\begin{tabular}{lccc}
\hline \multirow{2}{*}{ Municípios } & $N^{0}$ propriedades & \multicolumn{2}{c}{ Amostra } \\
\cline { 3 - 4 } & & Bovinos & Búfalos \\
\hline Marabá & 6 & 150 & 88 \\
Itupiranga & 4 & 75 & 65 \\
Xinguara & 4 & 80 & 55 \\
Rio Maria & 5 & 90 & 45 \\
Curionópolis & 5 & 88 & 44 \\
Santa Maria das Barreiras & 3 & 56 & 38 \\
Bannach & 4 & 60 & 50 \\
Água Azul do Norte & 4 & 80 & 45 \\
\hline Total & $\mathbf{3 5}$ & $\mathbf{6 7 9}$ & $\mathbf{4 3 0}$ \\
\hline
\end{tabular}

Fonte: Elaboração dos autores.

Para a análise estatística dos dados comparativos da ocorrência de anticorpos contra cada agente em bovinos e bubalinos foi utilizado o teste de Fisher com 95\% de confiança. Os procedimentos operacionais foram feitos utilizando o software R-Studio, versão 2.12.2 (2011). Para a análise epidemiológica dos dados, foi calculada a Razão de Prevalência (RP).

\section{Resultados e Discussão}

Os resultados absolutos da ocorrência de anticorpos da classe IgG anti-A. marginale, B. bovis e $B$. bigemina observada em bovinos e bubalinos da mesorregião sudeste do estado do Pará estão apresentados nas Tabelas 2 e 3 respectivamente.

Tabela 2. Frequência absoluta de positivos (+) e negativos (-) ao ELISA indireto para Anaplasma marginale, Babesia bovis, Babesia bigemina em 679 bovinos nelore de diferentes cidades do estado do Pará, Brasil, no ano de 2012.

\begin{tabular}{lcc}
\hline \multirow{2}{*}{ Bovinos } & \multicolumn{2}{c}{ ELISA } \\
\cline { 2 - 3 } & $(+)$ & $(-)$ \\
Anaplasma marginale & $\mathrm{n}(\%)$ & $\mathrm{n}(\%)$ \\
Babesia bigemina & $506(74.5)$ & $173(25.5)$ \\
Babesia bovis & $661(97.3)$ & $18(2.7)$ \\
\hline
\end{tabular}

Fonte: Elaboração dos autores. 
A ocorrência global de anticorpos encontrada em bovinosparaosagentes daTPBfoipredominantemente superior $(\mathrm{p}<0.05)$ que a observada em bubalinos. A probabilidade de um bovino ser sorologicamente positivo para $A$. marginale, B. bovis e B. bigemina foi $1,5(74,52 / 47,90 \%), 3,58(97,34 / 27,21 \%)$ e 2,87 $(97,34 / 33,95 \%)$ vezes maior, respectivamente, em relação aos búfalos. Este fato pode ser resultado da rusticidade dos búfalos, que apresentam uma menor taxa de infestação por carrapatos quando comparados com bovinos (STARKE; EVANGELISTA; ZOCOLLER, 1994; NITHIKATHKUL et al., 2002; SILVA et al., 2014), pois a maioria das larvas não conseguem chegar a fase adulta. Parâmetros biológicos de teleóginas alimentadas em bubalinos são diminuídos quando comparados a alimentação em bovinos (BENITEZ; CETRA; FLORIN-CHRISTENSEN, 2012). O gado zebuíno é conhecido por possuir uma maior resistência a carrapatos em relação às raças taurinas (CLEVES, 2006), mesmo assim eles, provavelmente, são mais susceptíveis à infestação por carrapatos que os bubalinos. No entanto, a quantificação de ectoparasitas nestes animais não foi realizada, e desta forma, não foi possível realizar um estudo comparativo entre a infestação por carrapatos e a infecção por hemoparasitos.

Tabela 3. Frequência absoluta de positivos (+) e negativos (-) ao ELISA indireto para Anaplasma marginale, Babesia bovis, Babesia bigemina em 430 bubalinos de diferentes cidades do estado do Pará, Brasil, no ano de 2012.

\begin{tabular}{lcc}
\hline \multirow{2}{*}{ Búfalos } & \multicolumn{2}{c}{ ELISA } \\
\cline { 2 - 3 } & $(+)$ & $(-)$ \\
Anaplasma marginale & $\mathrm{n}(\%)$ & $\mathrm{n}(\%)$ \\
Babesia bigemina & $206(47.9)$ & $224(52.1)$ \\
Babesia bovis & $117(27.2)$ & $313(72.8)$ \\
\hline
\end{tabular}

Fonte: Elaboração dos autores.

Dentre os hemoparasitos testados no ELISA indireto, B. bovis e $B$. bigemina foram os mais prevalentes nos bovinos (97,34\%), seguido de $A$. marginale $(74,52 \%)$ (Tabela 1$)$. Porém a ocorrência total de $A$. marginale (47,90\%) nos bubalinos avaliados foi a maior quando comparado aos outros hemoparasitos testados (Tabela 2). Esse fato pode estar relacionado a outras fontes de infecção, pois Anaplasma marginale também pode ser transmitido mecanicamente, através de insetos hematófagos e fômites (KESSLER, 2001; KOCAN et al., 2010).

A ocorrência sorológica para os três agentes em bovinos observada no presente estudo corrobora com os resultados encontrados na região nordeste do estado do Pará por Guedes Junior et al. (2008). Em um estudo realizado no semi-árido da Bahia a ocorrência de anticorpos anti- $B$. bigemina, $B$. bovis e $A$. marginale foi de 77,7\%, 75,5\% e 98,9\%, respectivamente (BARROS et al., 2005). Em búfalos a frequência sorológica para B. bovis $(33,95 \%)$ e $B$. bigemina $(27,21 \%)$, determinada através do ELISA indireto, neste estudo, foram superiores aos encontrados por He et al. (2012) na China, por Terkawi et al. (2012) na Síria e por Terkawi et al. (2011) na Tailândia e inferiores aos resultados de Corrêa (2011) no estado do Rio de Janeiro, Brasil. Em relação à frequência de anticorpos $\operatorname{IgG}$ de búfalos anti- $A$. marginale na mesorregião sudeste paraense $(47,90 \%)$, os resultados corroboram com Corrêa (2011) (43,00\%).

Segundo a classificação matemática de Mahoney e Ross (1972) a prevalência encontrada em bovinos no presente estudo é considerada como estável para agentes da TPB, caracterizando-se, portanto, 
como uma região com baixo risco de surtos, porém devido à expressiva taxa de soropositivos, a região oferece elevado risco para a introdução de animais não adaptados ou de áreas de instabilidade enzoótica para anaplasmose e babesiose bovinas. Nesse estudo, os animais amostrados são bovinos de corte abatidos para carne de exportação, por esse motivo, um surto de TPB representaria uma perda econômica de grande impacto. Em contrapartida, a frequência sorológica observada nos bubalinos da mesorregião sudeste paraense foi considerada instável usando o mesmo critério.

Desta forma, como também ocorre na Ilha de Marajó-PA (SILVA et al., 2013a; SILVA et al., 2014), os bubalinos poderão atuar como reservatórios dos agentes da TPB, representando um risco para o rebanho onde búfalos e bovinos são mantidos juntos (SILVA et al., 2013b). A prevalência de animais soropositivos para agentes transmitidos por carrapatos sugere um estudo mais detalhado da epidemiologia da TPB, em bovinos e bubalinos, na região.

\section{Agradecimentos}

Ao Conselho Nacional de Desenvolvimento Científico e Tecnológico (CNPq) pelo apoio financeiro. à Professora Rosangela Zacarias Machado (FCAV/UNESP) por gentilmente ceder o antígeno utilizado.

\section{Referências}

BARROS, S. L; MADRUGA, C. R.; ARAÚJO, F. R.; MENK, C. F.; ALMEIDA, M. A. O. de; MELO, E. P.; KESSLER, R. H. Serological survey of Babesia bovis, Babesia bigemina, and Anaplasma marginale antibodies in cattle from the semi-arid region of the state of Bahia, Brazil, by enzyme-linked immunosorbent assays. Memórias do Instituto Oswaldo Cruz, Rio de Janeiro, v. 100, n. 6, p. 513-517, out. 2005.

BENITEZ, D.; CETRÁ, B.; FLORIN-CHRISTENSEN, M. Rhipicephalus (Boophilus) microplus ticks can complete their life cycle on the Water Buffalo (Bubalus bubalis). Journal of Buffalo Science, Mississauga, v. 1, n. 2, p. 193-197, ago. 2012.

BOCK, R.; JACKSON, L.; VOS, A. de; JORGENSEN, W. Babesiosis of cattle. Parasitology, Cambrigde, v. 129, n. 1, p. 247-269, out. 2004.

CLEVES, V. C. Los cruzamientos genéticos una alternativa para el control de la garrapata común del ganado Boophilus microplus en sudamérica. Buenos Aires: Sitio Argentino de Producción Animal, 2006. p. 1-4. Disponível em: $<$ http://www.produccionanimal.com. ar/sanidad_intoxicaciones_metabolicos/parasitarias/ Bovinos_garrapatas_tristeza/00-Bovinos_garrapatas_ tristeza.html>. Acesso em: 20 jul. 2012.

CORRÊA, F. N. Estudo epidemiológico de Borrelia burgdorferi, Babesia bovis, Babesia bigemina e Anaplasma marginale em búfalos (Bubalus bubalis) do Estado do Rio de Janeiro. 2011. Tese (Doutorado em Ciências Veterinárias) - Universidade Federal Rural do Rio de Janeiro, Seropédica.

GUEDES-JUNIOR, D. S.; ARAÚJO, F. R.; SILVA, F. J. M.; RANGEL, C. P.; BARBOSA-NETO, J. D.; FONSECA, A. H. Frequency of antibodies to Babesia bigemina, B. bovis, Anaplasma marginale, Trypanosoma vivax and Borrelia burdgorferi in cattle from the northeastern region of the state of Pará, Brazil. Revista Brasileira de Parasitologia Veterinária, Jaboticabal, v. 17, n. 2, p. 105-109, abr./jun. 2008.

HE, L.; FENG, H. H.; ZHANG, W. J.; ZHANG, Q. L.; FANG, R.; WANG, L. X.; TU, P.; ZHOU, Y. Q.; ZHAO, J. L.; OOSTHUIZEN, M. C. Occurrence of Theileria and Babesia species in water buffalo (Bubalus babalis Linnaeus, 1758) in the Hubei province, South China. Veterinary Parasitology, Amsterdam, v. 186, n. 3, p. 490496, maio 2012.

KESSLER, R. H. Considerações sobre a transmissão de Anaplasma marginale. Pesquisa Veterinária. Brasileira, Seropédica, v. 21, n. 4, p. 177-179, dez. 2001.

KOCAN, K. M.; DE LA FUENTE, J.; BLOUIN, E. F.; COETZEE, J. F.; EWING, S. A. The natural history of Anaplasma marginale. Veterinary Parasitology, Amsterdam, v. 167, n. 2-4, p. 95-107, fev. 2010.

MACHADO, R. Z.; MONTASSIER, H. J.; PINTO, A. A.; LEMOS, E. G.; MACHADO, M. R. F.; VALADÃO, I. F. F.; BARCI, L. G.; MALHEIROS, E. B. An enzymelinked immunosorbent assay (ELISA) for the detection on antibodies against Babesia bovis in cattle. Veterinary Parasitology, Amsterdam, v. 71, n. 1, p. 17-26, jul. 1997.

MAHONEY, D. F.; ROSS, D. R. Epizootiological factors in the control of bovine babesiosis. Australian Veterinary Journal, Oxford, v. 48, n. 1, p. 292-298, maio 1972. 
NITHIKATHKUL, C.; POLSEELA, P.; CHANGSAP, B.; LEEMINGSAWAT, S. A Study of ixodid ticks on domestic animals in Samut Prakan Province, Thailand. Southeast Asian Journal Tropical Med Public Health, Bangkok, v. 33, n. 1, p. 41-44, mar. 2002.

R DEVELOPMENT CORE TEAM. R: a language and environment for statistical computing. Vienna: $\mathrm{R}$ Foundation for Statistical Computing, 2011. Available at: $<$ http://www.R-project.org >. Access at: 20 fev. 2011.

SILVA, J. B.; ANDRÉ, M. R.; FONSECA, A. H.; LOPES, C. T. A.; LIMA, D. H. S.; ANDRADE, S. J. T.; OLIVEIRA, C. M. C.; BARBOSA, J. D. Molecular and serological prevalence of Babesia bovis and Babesia bigemina in water buffaloes in the north region of Brazil. Veterinary Parasitology, Amsterdam, v. 197, n. 1, p. 678681, 2013a.

SILVA, J. B.; LOPES, C. T. A.; PINHEIRO, C. P.; SILVA, R. S. L.; FONSECA, A. H.; ARAÚJO, F. R.; BARBOSANETO, J. D. Prevalência sorológica e molecular de Babesia bovis e Babesia bigemina em búfalos (Bubalus bubalis) na Ilha de Marajó, Pará. Pesquisa Veterinária Brasileira, Seropédica, v. 33, n. 7, p. 847-850, jul. 2013b.

SILVA, J. B.; VINHOTE, W. M. S.; OLIVEIRA, C. M. C.; ANDRÉ, M. R.; FONSECA, A. H.; MACHADO, R. Z.; BARBOSA, J. D. Molecular and serological prevalence of Anaplasma marginale in water buffaloes in the northern Brazil. Ticks and Tick Borne Diseases, Amsterdam, v. 5, n. 1, p. 100-104, mar. 2014.

STARKE, W. A.; EVANGELISTA, F. M. M.; ZOCOLLER, M. C. Comparative study of the natural infestion by Boophilus microplus tick between buffalo and cattle. In: WORLD BUFALLO CONGRESS, 4., 1994, São Paulo. Anais... São Paulo: World Buffalo Breeding Association e Sociedade Brasileira de Criadores de Búfalos, 1994. 102 p.

TERKAWI, M. A.; ALHASAN, H.; HUYEN, N. X.; SABAGH, A.; AWIER, K.; CAO, S.; GOO, Y. K.; ABOGE, G.; YOKOYAMA, N.; NISHIKAWA, Y.; KALB-ALLOUZ, A. K.; TABBAA, D.; IGARASHI, I.; XUAN, X. Molecular and serological prevalence of Babesia bovis and Babesia bigemina in cattle from central region of Syria. Veterinary Parasitology, Amsterdam, v. 187, n. 1, p. 307-311, jun. 2012.

TERKAWI, M. A.; HUYEN, N. X.; SHINUOA, C.; INPANKAEWB, T.; MAKLONC, K.; ABOULAILAA, M.; UENOA, A.; GOOA, Y. K.; YOKOYAMAA, N.; JITTAPALAPONGB, S.; XUANA, X.; IGARASHIA, I. Molecular and serological prevalence of Babesia bovis and Babesia bigemina in water buffaloes in the northeast region of Thailand. Veterinary Parasitology, Amsterdam, v. 178 , n. 3 , p. 201-207, jun. 2011. 